\title{
RESEARCH
}

Open Access

\section{Impact of human adipose tissue-derived stem cells on dermatofibrosarcoma protuberans cells in an indirect co-culture: an in vitro study}

Zhaoqi Yuan ${ }^{1,2+}$, Zhu Zhu ${ }^{1,2+}$, Fangxing Zhu ${ }^{3+}$, Feixue Ding ${ }^{1,2}$, Yinmin Wang ${ }^{1,2}$, Xiuxia Wang ${ }^{1,2}$, Xusong Luo , Jun Yang ${ }^{1}$, Fei Liu ${ }^{1 *+}$ and Di Sun ${ }^{1 *+}$

\begin{abstract}
Background: Autologous adipose tissue transfer may be performed for aesthetic needs following the resection of dermatofibrosarcoma protuberans (DFSP), the most common cutaneous soft tissue sarcoma, excluding Kaposi sarcoma. The regenerative effectiveness of cell-assisted lipotransfer is dependent on the presence of adipose tissuederived stem cells (ADSCs). This is the first study to evaluate the potential oncological risks as ADSCs could unintentionally be sited within the proximity of the tumor microenvironment of DFSP cells.

Methods: Primary DFSP cells were indirectly co-cultured with ADSCs in a conditioned medium or in a Transwell system. The impact was analyzed by assessing proliferation, migration, invasion, angiogenesis, and tumor-associated genes and proteins. Results of these assays were compared between co-culture and mono-culture conditions.

Results: Our experimental results showed that ADSCs were able to promote proliferation, migration, invasion, and angiogenesis of DFSP cells; this was accompanied by a significant increase in the expression levels of beta-type platelet-derived growth factor receptor, collagen type I alpha 1 chain, vascular endothelial growth factor, hepatocyte growth factor, and basic fibroblast growth factor.
\end{abstract}

Conclusions: The current report clearly demonstrates that ADSCs can enhance different malignant properties of DFSP cells in vitro, which should not be neglected when considering the clinical use of human ADSCs and its related derivatives in skin regenerative therapies.

Keywords: Dermatofibrosarcoma protuberans (DFSP), Adipose tissue-derived stem cells (ADSCs), Skin therapy, Regenerative medicine

\footnotetext{
* Correspondence: Plasticliu@hotmail.com; sundi1980hn@sina.com

${ }^{\dagger}$ Zhaoqi Yuan, Zhu Zhu and Fangxing Zhu contributed equally to this work

and should be considered as co-first authors.

${ }^{\dagger}$ Di Sun and Fei Liu contributed equally to this work and should be

considered as co-corresponding authors.

'Department of Plastic and Reconstructive Surgery, Shanghai Ninth People's

Hospital, Shanghai Jiao Tong University School of Medicine, Shanghai

200011, China

Full list of author information is available at the end of the article
}

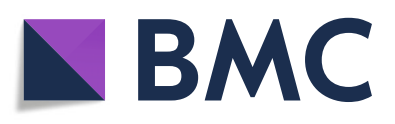

(- The Author(s). 2021 Open Access This article is licensed under a Creative Commons Attribution 4.0 International License, which permits use, sharing, adaptation, distribution and reproduction in any medium or format, as long as you give appropriate credit to the original author(s) and the source, provide a link to the Creative Commons licence, and indicate if changes were made. The images or other third party material in this article are included in the article's Creative Commons licence, unless indicated otherwise in a credit line to the material. If material is not included in the article's Creative Commons licence and your intended use is not permitted by statutory regulation or exceeds the permitted use, you will need to obtain permission directly from the copyright holder. To view a copy of this licence, visit http://creativecommons.org/licenses/by/4.0/ The Creative Commons Public Domain Dedication waiver (http://creativecommons.org/publicdomain/zero/1.0/) applies to the data made available in this article, unless otherwise stated in a credit line to the data. 


\section{Background}

Human mesenchymal stem/stromal cells (hMSCs) are a heterogeneous ensemble of cells with fibroblast-like morphology and can proliferate and form colonies in vitro. Additionally, hMSCs are capable of undergoing multilineage differentiation. Owing to the beneficial immunomodulatory and regenerative properties of hMSCs, these cells have received significant attention as potential agents for therapies [1]. Adipose tissue-derived stem cells (ADSCs), an abundant and readily available subset of hMSCs, can be largely extracted from subcutaneous human adipose tissue; thus, they are one of the most suitable cell sources for stem cell-based therapies [2]. ADSCs have tremendous plasticity with tri-lineage differentiation potential; these cells can differentiate into osteocytes, chondrocytes, and adipocytes [3]. ADSCs can affect cells in their microenvironment through the paracrine secretion of proteins [4]. Owing to their selfrenewal, unlimited proliferative, proangiogenic, and immunomodulatory properties, ADSCs have been used as attractive adjuncts in the form of cell-assisted lipotransfer to improve wound healing, angiogenesis, tissue engineering, and soft tissue augmentation after reconstructive surgery [5]. Recently, it has been reported that ADSCs loaded with biomaterials as antitumor drug carriers selectively target solid tumors during thermo-/chemotherapy. This can improve the typical drug delivery methods, correlating with magnetic resonance imaging tracking for diagnostic applications [6, 7].

Interestingly, ADSCs have also been shown to exhibit duality. These cells not only greatly promote cell regeneration but also facilitate the progression of tumors [1, 8]. ADSCs have been reported to be actively recruited into the tumor nidus and surrounding inflammatory microenvironment by cancer cells, thus increasing tumor vascularity [9]. Moreover, ADSCs have been suggested to differentiate into cancer-associated fibroblasts (CAFs), which form an essential part of the tumor stroma [10]. Therefore, they serve as an important promoter of tumor growth, invasion, and metastasis through the secretion of various cytokines and proteases [11, 12]. Additionally, ADSCs are similar to CAFs in their cancer-promoting properties; therefore, ADSCs interact within the tumor microenvironment (TME), promoting cancer cell proliferation, viability, invasiveness, and chemoresistance [3]. Consequently, there have been concerns regarding the oncological safety of using ADSCs in cell-based regenerative therapy for reconstruction after cancer surgery [8]. Although studies focusing on ADSCs and tumors have been gaining attention, none of these studies have examined the impact of ADSCs on dermatofibrosarcoma protuberans (DFSP).

DFSP is a rare, low-grade, soft tissue sarcoma; it is the most common type of cutaneous soft tissue sarcoma, excluding Kaposi sarcoma [13]. Problems such as initial misdiagnoses, prolonged time to accurate diagnosis, and large tumor size at the time of diagnosis are common because of the lack of specific DFSP characteristics [14]. In addition, with highly irregular shapes [15], these tumor cells often infiltrate the dermis and spread into the underlying subcutaneous tissue, which results in an incomplete resection and a high recurrence rate of DFSP [16]. Hence, to achieve clear surgical margins, extended excision is necessary, which causes large defects in the skin and soft tissue. It is challenging for plastic and reconstructive surgeons to repair thesis defects, including morphological alteration and function loss. Most recently, some studies have mentioned fat grafting at the surgical site of malignant neoplasms of mesenchymal origin, although these studies have cautioned against its potential safety issues [17]. Evidence of the oncological safety of fat grafting after cancer surgery is based primarily on clinical studies in breast cancer and is limited by possible bias. The biology of sarcoma is relatively different from that of breast carcinoma. The unclear and diverse etiopathogenesis of sarcomas and high risk of local recurrence combined with the variable signaling of the fat microenvironment, including ADSCs and related growth factors, should be investigated more extensively [17].

Therefore, considering the growing use of fat, stem cell-enriched, and isolated ADSCs in defects of the skin and soft tissues after radical tumor resection, it is important to identify the oncological safety of possible interactions between co-localized ADSCs and DFSP cells. Unfortunately, there is no report on this issue. This is the first study to co-culture primary DFSP cells with ADSCs. Subsequently, we quantified the changes in proliferation, migration, invasion, and angiogenesis and compared the results with those of DFSP cell monocultures. In addition, we aimed to obtain further insight into the interactions from the perspective of genes and proteins. If ADSCs exert a promoting effect on DFSP cells, it may alert plastic surgeons about potential safety issues as these ADSCs are injected into a surgical site where possibly residual or dormant DFSP cells can survive and develop.

\section{Methods}

Adipose tissue-derived stem cell (ADSC) isolation, cultivation, and identification

Human adipose tissue samples were obtained by liposuction of the abdominal wall from three different donors. After rinsing three times with phosphate-buffered saline (PBS), the samples were digested with $0.1 \%(\mathrm{w} / \mathrm{v})$ collagenase IV (NB4; Serva, Heidelberg, Germany) for 2 h. Cells were concentrated by centrifugation at $1500 \mathrm{rpm}$ at $37^{\circ} \mathrm{C}$ for 5 min to obtain ADSCs. ADSCs were cultured in lowglucose Dulbecco's modified Eagle's medium (DMEM; 
Hyclone, Logan, UT, USA) supplemented with $10 \%$ fetal bovine serum (FBS; ScienCell Research Laboratories, Inc., San Diego, CA, USA), $100 \mathrm{U} / \mathrm{mL}$ penicillin, and $100 \mu \mathrm{g} /$ $\mathrm{mL}$ streptomycin (Gibco; Thermo Fisher Scientific, Inc., Waltham, MA, USA) at $37^{\circ} \mathrm{C}$ in $5 \% \mathrm{CO}_{2}$ until they reached $80-90 \%$ confluence. Thereafter, they were dissociated with $0.05 \%$ trypsin-ethylenediaminetetraacetic acid and passaged. The cells of passages 2-6 were combined and used for further characterization and in vitro differentiation [18].

\section{ADSC identification}

The capacity of ADSCs to differentiate into osteoblasts, chondrocytes, and adipocytes was assessed as described [19-21].

\section{Osteogenic differentiation assay}

Human ADSCs $\left(2 \times 10^{4}\right.$ cells $\left./ \mathrm{cm}^{2}\right)$ were seeded in sixwell plates that were pre-coated with a $0.1 \%$ gelatin solution and then cultured in DMEM containing 10\% FBS, $1 \%$ antibiotic/antimycotic, $0.01 \mu \mathrm{M}$ 1,25-dihydroxyvitamin D3, $50 \mu \mathrm{M}$ ascorbate-2-phosphate, and $10 \mathrm{mM} \beta$ glycerophosphate (HUXMD-90021, Cyagen Bioscience, Inc., Santa Clara, CA, USA). The medium was changed every 3 days. After 28 days of culture at $37^{\circ} \mathrm{C}$ under $5 \%$ $\mathrm{CO}_{2}$, the cells were washed twice with PBS, fixed in $4 \%$ paraformaldehyde for $30 \mathrm{~min}$, and stained with $0.3 \%$ Alizarin red for $5 \mathrm{~min}$. After two washes with PBS, the cells were observed and photographed under a phase-contrast inverted microscope (Olympus, Tokyo, Japan).

\section{Chondrogenic differentiation assay}

Human ADSCs $\left(4 \times 10^{5}\right.$ cells $)$ were seeded in $15 \mathrm{~mL}$ centrifuge tubes filled with DMEM containing 10\% FBS, 1\% antibiotic/antimycotic, $6.25 \mu \mathrm{g} / \mathrm{mL}$ insulin, $10 \mathrm{ng} / \mathrm{mL}$ transforming growth factor-beta 1 , and $50 \mathrm{nM}$ ascorbate2-phosphate (HUXMD-90041, Cyagen Bioscience, Inc.). The medium was changed every 3 days. After 28 days of culture at $37^{\circ} \mathrm{C}$ under $5 \% \mathrm{CO}_{2}$, the cartilage balls were formalin-fixed, paraffin-embedded, sectioned, and stained with Alcian blue. The sections were observed and photographed under a light microscope (Leica Microsystems GmbH, Wetzlar, Germany).

\section{Adipogenic differentiation assay}

Human ADSCs $\left(2 \times 10^{4}\right.$ cells $\left./ \mathrm{cm}^{2}\right)$ were seeded in six-well plates in DMEM containing 10\% FBS, $1 \%$ antibiotic/antimycotic solution, $0.5 \mathrm{mM}$ isobutyl-methylxanthine, $1 \mu \mathrm{M}$ dexamethasone, $10 \mu \mathrm{M}$ insulin, and $200 \mu \mathrm{M}$ indomethacin (Cyagen Bioscience, Inc., HUXMD-90031). The medium was changed every 3 days. After 28 days of culture at $37^{\circ} \mathrm{C}$ under $5 \% \mathrm{CO}_{2}$, the cells were washed twice with PBS, fixed in $4 \%$ paraformaldehyde for $30 \mathrm{~min}$, and stained with $0.3 \%$ oil red $\mathrm{O}$ solution for $30 \mathrm{~min}$. After two washes with
PBS, the cells were observed and photographed under a phase-contrast inverted microscope (Olympus).

\section{Flow cytometric assay}

Flow cytometric analysis was used to identify the markers of ADSCs according to a published paper [22]. Briefly, hADSCs were harvested and washed thrice with PBS. The cell suspension was incubated with fluorescein isothiocyanate-conjugated antibodies against CD29, CD31, CD45, and CD90 (Santa Cruz Biotechnology, Inc., Santa Cruz, CA, USA) and phycoerythrinconjugated antibodies against CD105 and CD44 (Santa Cruz Biotechnology, Inc.) at $37^{\circ} \mathrm{C}$ for $30 \mathrm{~min}$ in the dark, washed, and resuspended in PBS and subjected to flow cytometry (BD Biosciences, San Jose, CA, USA).

\section{Dermatofibrosarcoma protuberans (DFSP) cell isolation and cultivation}

Three DFSP samples from one man and two women were obtained after excision from the corresponding sites (Table 1). Samples were soaked in chloromycetin for $30 \mathrm{~min}$, cut into as small pieces as possible, and then digested with $0.1 \%$ collagenase IV for $30 \mathrm{~min}$ at $37^{\circ} \mathrm{C}$. After centrifugation, cells were suspended in highglucose DMEM (Hyclone, Logan, UT, USA) with $10 \%$ FBS, $100 \mathrm{U} / \mathrm{mL}$ penicillin, and $100 \mathrm{mg} / \mathrm{mL}$ streptomycin at $37^{\circ} \mathrm{C}$ in $5 \% \mathrm{CO}_{2}$. Cells at passages $2-6$ were used in this experiment $[23,24]$.

\section{DFSP-ADSC co-cultures}

\section{Indirect co-culture by a conditioned medium}

To prepare a human ADSC conditioned medium (CM) [25], $2 \times 10^{5}$ ADSCs were seeded onto a six-well cell culture plate with DMEM/F12 (Hyclone, Logan, UT, USA) medium containing 10\% FBS overnight, and the culture medium was replaced with DMEM/F12 serum-free (SF) and conditioned for $24 \mathrm{~h}$. ADSC-CM was harvested, filtered through $0.22-\mu \mathrm{m}$ filters (Jet Bio-Filtration, Guangzhou, China), and stored at $-80^{\circ} \mathrm{C}$ until use.

\section{Indirect co-culture by a Transwell system}

Co-culture of DFSP cells and ADSCs was performed using a Transwell system (Fig. 1) [12, 25, 26]. First, $2 \times 10^{5}$ ADSCs were seeded onto a polyester membrane Transwell-clear insert (pore size $0.4 \mu \mathrm{m}$, Corning Incorporated, Corning, NY, USA). Next, DFSP cells were

Table 1 Clinical information of patients with dermatofibrosarcoma protuberans

\begin{tabular}{llll}
\hline Sample & Sex & Age & Location \\
\hline 1 & 1 & $30-39$ & Anterior chest \\
2 & 2 & $40-49$ & Abdomen \\
3 & 1 & $40-49$ & Left clavicle \\
\hline
\end{tabular}




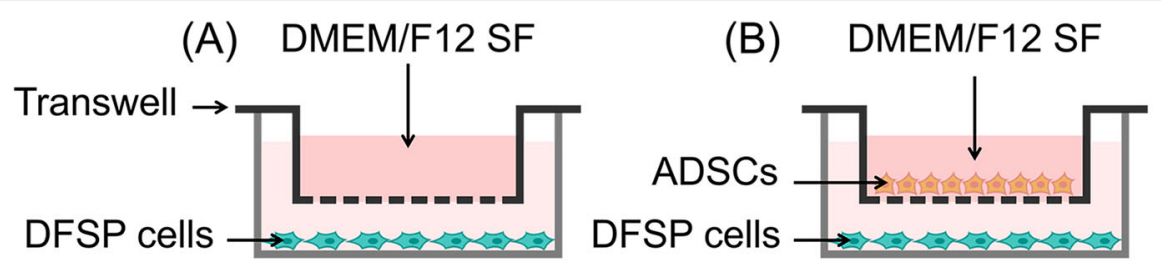

Mono-cultured DFSP cells Co-cultured DFSP cells

Fig. 1 Model of DFSP cells co-cultured with ADSCs by Transwell. A DFSP cells cultured alone and B DFSP cells co-cultured with ADSCs in DMEM/ F12 SF. ADSCs, adipose tissue-derived stem cells; DFSP, dermatofibrosarcoma protuberans; DMEM, Dulbecco's modified Eagle's medium; SF, serum-free

seeded onto the bottom of a six-well cell culture plate with the same cell density in DMEM/F12 medium containing 10\% FBS overnight. Subsequently, the medium was replaced with fresh DMEM/F12 SF to eliminate non-adherent cells. At the required time point, DFSP cells or supernatants (co-cultured DFSP/ADSC-CM) were collected and stored at $-80^{\circ} \mathrm{C}$ until use. Isolated DFSP cells seeded on six-well culture plates served as controls and were treated as the co-cultured cells.

\section{Proliferation assays}

The ability of ADSC-CM to induce DFSP cell proliferation was assessed using a Cell Counting Kit-8 (CCK-8) (Dojindo Laboratories, Kumamoto, Japan) according to the manufacturer's protocols [23, 27]. Briefly, DFSP cells $\left(2 \times 10^{3} /\right.$ well $)$ were seeded in 96-well plates. After $24 \mathrm{~h}$, the DFSP cells were treated with ADSC-CM (supplemented with 1\% FBS) and DMEM/F12 (supplemented with $1 \% \mathrm{FBS}$ ) as a control. The medium was replaced every $48 \mathrm{~h}$. After 1, 3, 5, and 7 days, the cells were washed three times with PBS, and $100 \mu \mathrm{L}$ of fresh culture medium with $10 \mu \mathrm{L}$ of CCK-8 reagent was added to each well and incubated at $37^{\circ} \mathrm{C}$ for $2 \mathrm{~h}$. The absorbance of each sample, which was proportional to the number of viable cells, was measured at a wavelength of $450 \mathrm{~nm}$ using a microplate reader (Thermo Fisher Scientific, Waltham, MA, USA). Each group was prepared in triplicates. The experiment was repeated three times.

\section{Cell migration assays}

\section{Scratch wound healing}

DFSP cells $\left(2 \times 10^{5} /\right.$ well $)$ were seeded in six-well culture plates and grown in a complete medium until they reached $80 \%$ confluence. Subsequently, monolayers were scratched using a $200-\mu \mathrm{L}$ sterile plastic pipette tip (PipetTipFinder, LLC, Knoxville, TN, USA), which was placed perpendicular to the bottom of the dish as previously described and then washed three times with PBS [28]. DFSP cells were then treated with ADSC-CM SF for $24 \mathrm{~h}$. Positive controls were set up with DMEM/ F12+10\% FBS and negative controls with DMEM/F12
SF. Scratch wound closure was monitored using a phasecontrast inverted microscope (Olympus) at 0, 6, 12, and $24 \mathrm{~h}$. It was then employed to measure the area between the opposite edges of the wound, which was semiquantified with ImageJ software 1.46r (National Institutes of Health, USA). The migration rate was calculated using the following formula: migration rate $(\%)=(\mathrm{Gap} 0 \mathrm{~h}-$ Gap24h)/Gap0h $\times 100 \%$. In each sample, five views were randomly photographed to obtain the mean, and the final mean rate plus standard deviation $($ mean $\pm S D)$ was derived from the means of three cell samples [18].

\section{Transwell assay}

Cell migration [12, 25, 26] was also evaluated using a 24-well Transwell chamber (Corning, pore size $8.0 \mu \mathrm{m}$ ). For this purpose, once $80 \%$ confluence was achieved, DFSP cells were collected and seeded in the upper chamber of an $8.0-\mu \mathrm{m}$ pore size insert $(2 \times 104$ cells/well $)$ with DMEM/F12 SF and allowed to migrate toward DMEM/F12+10\% FBS (positive control), DMEM/F12 SF (negative control), or ADSCs $(2 \times 104$ cells/well; experimental) present in the lower chamber. After incubation for 12 and $24 \mathrm{~h}$, the non-migrating cells in the upper chamber were removed with a cotton swab, and the remaining cells were fixed in methanol for $30 \mathrm{~min}$. Cells that migrated to the lower surface of the membrane were stained with $0.5 \%$ crystal violet, diluted for $5 \mathrm{~min}$, gently washed three times in PBS, air-dried, and observed and photographed with a microscope (Olympus). Five fields were randomly selected for each assay. Quantification was performed by processing all obtained images using ImageJ software 1.46r (National Institutes of Health). The average number of migrating cells in five random fields was taken as the cell migration number of the group. All experiments were repeated three times.

\section{Cell invasion assay}

The capacity of ADSC-CM to induce DFSP cell invasion was tested using a 24-well Transwell chamber $(8-\mu \mathrm{m}$ pore size insert) pre-coated with Matrigel matrix (Cat. No. 356234, Corning Incorporated) according to the 
manufacturer's instructions [12, 25, 26]. Briefly, $100 \mu \mathrm{L}$ of the diluted Matrigel matrix $(800 \mu \mathrm{g} / \mathrm{mL}$ in $\mathrm{SF}$ medium) was carefully added to the center of each Transwell insert for invasion assays. The plate was incubated at $37^{\circ} \mathrm{C}$ for $1 \mathrm{~h}$ to allow the Matrigel to form a gel. The DFSP cells were counted and diluted to a density of $2 \times 10^{5}$ cells $/ \mathrm{mL}$ with $\mathrm{DMEM} / \mathrm{F} 12+10 \%$ FBS (positive control), DMEM/F12 SF (negative control), and ADSC$\mathrm{CM}$ (experimental). Next, $100 \mu \mathrm{L}$ of the cell suspension was seeded into the upper chamber of each Transwell. Thereafter, $800 \mu \mathrm{L}$ of culture medium with $5 \%$ FBS was added to the lower chambers. The cells were cultured in a humidified incubator at $37^{\circ} \mathrm{C}$ with $5 \% \mathrm{CO}_{2}$ for $36 \mathrm{~h}$. The cells inside the Transwell inserts were gently removed using cotton swabs, and the cells on the lower surface of the membrane were stained with crystal violet for $5 \mathrm{~min}$. The Transwell inserts were washed three times with PBS to remove unbound crystal violet and then air-dried. The invaded cells were observed and photographed under a microscope (Olympus). Five fields were randomly selected for each assay. Quantification was performed by processing all obtained images using ImageJ software 1.46r (National Institutes of Health). The average number of migrating cells in these five fields was taken as the cell invasion number of the group. All experiments were repeated three times.

\section{Angiogenic properties assay}

To evaluate the effect of proteins secreted by isolated DFSP cells or ADSCs or both co-cultured cells on angiogenesis, SF CM of each condition was collected at $24 \mathrm{~h}$ of cell culture (processing with the abovementioned method). $\mathrm{Hu}-$ man umbilical vein endothelial cells (HUVECs) were obtained from the Cell Bank of the Shanghai Institute of Cell Biology, Chinese Academy of Sciences (Shanghai, China). Wells of a 96-well plate were coated with Matrigel matrix, and $1 \times 10^{4}$ HUVECs were seeded onto the matrix in each well. The ADSC-CM, DFSP-CM, and co-cultured DFSP/ADSC-CM were added and incubated for $4 \mathrm{~h}$. Tube formation was visualized using bright-field microscopy. Quantification was performed by processing all obtained images using ImageJ software 1.46r (National Institutes of Health). The experiments were independently reproduced at least three times $[12,29,30]$.

\section{Quantitative real-time polymerase chain reaction}

After $24 \mathrm{~h}$ of co-culture (processing with the above method found in the "Indirect co-culture by a Transwell system" section), total RNA was extracted using EZ-press RNA Purification Kit (B0004D, EZBioscience, Roseville, USA) according to the manufacturer's instructions [3133]. RNA purity was evaluated by calculating the A260/ A280 ratio, which should be between 1.8 and 2.0. The mRNA was reverse transcribed into cDNA with
$4 \times$ Reverse Transcription Master Mix (A0010, EZBioscience). Subsequently, real-time quantitative realtime polymerase chain reaction (qRT-PCR) was performed using the cDNA as a template and $2 \times$ SYBR Green qPCR Master Mix (A0001, EZBioscience) according to the manufacturer's instructions. Primers were synthesized by Sangon Biotech Co. (Shanghai, China). Target gene expression levels were normalized to glyceraldehyde 3phosphate dehydrogenase and quantified using the comparative Ct method. The mean minimal cycle threshold value was calculated from triplicate reactions. The primers used for qRT-PCR analysis are listed in Table 2.

\section{Western blotting analysis}

After $48 \mathrm{~h}$ of co-culture (processing with the above method found in the "Indirect co-culture by a Transwell system" section), total protein was extracted from the DFSP cells with radioimmunoprecipitation assay lysis buffer as described previously [34]. Supernatants were collected, and their total protein concentration was determined using the BCA Protein Assay Kit (Cat. No. P0010, Beyotime, Shanghai, China). Protein samples were completely denatured by boiling in bromophenol blue sample buffer for 5 min, separated by electrophoresis on $7.5 \%$ sodium dodecyl sulfate-polyacrylamide gel, and then transferred onto polyvinylidene difluoride membranes. Non-specific antibody binding was blocked with $5 \%$ non-fat dry milk in Tris-buffered saline containing $0.1 \%$ Tween 20 for $1 \mathrm{~h}$ at room temperature. The primary antibodies used were as follows: beta-type platelet-derived growth factor receptor (PDGFRB) (1: 5000, Cat. No. ab32570, Abcam, Cambridge, MA, USA) and collagen type I alpha 1 chain (COL1A1) (1:1000, Cat. No. ab34710, Abcam). Immunoblotting was performed using specific primary antibodies and secondary antibodies conjugated to horseradish peroxidase. Protein blots were developed using an enhanced chemiluminescence method. $\beta$-actin (1:2000, Cat. No. ab8226, Abcam) was used as a loading control, and the results were analyzed as the detected $\beta$-actin ratio.

\section{Enzyme-linked immunosorbent assay}

After $48 \mathrm{~h}$ of culturing, supernatants were collected from the DFSP-mono-culture and DFSP-ADSC-co-culture in Transwell (processing with the above method found in the "Indirect co-culture by a Transwell system" section) and stored at $-80^{\circ} \mathrm{C}$ until use. The levels of vascular endothelial growth factor (VEGF), hepatocyte growth factor (HGF), and basic fibroblast growth factor (bFGF) were measured using an enzyme-linked immunosorbent assay (ELISA) kit (R\&D Systems, Inc., Minneapolis, MN, USA) according to the manufacturer's protocol $[35,36]$. Standard curves were generated to calculate the cytokine levels. The experiments were independently repeated thrice. 
Table 2 Primers for RT-PCR

\begin{tabular}{|c|c|c|}
\hline Gene & Forward primer (5'-3') & Reverse primer $\left(5^{\prime}-3^{\prime}\right)$ \\
\hline GAPDH & GGGAAGCTTGTCATCAATGGAA & AGAGATGATGACCCTITGGCTC \\
\hline PDGFRB & AGCACCTTCGTTCTGACCTG & TATTCTCCCGTGTCTAGCCCA \\
\hline COL1A1 & GAGGGCCAAGACGAAGACATC & CAGATCACGTCATCGCACAAC \\
\hline VEGF & AGGGCAGAATCATCACGAAGT & AGGGTCTCGATTGGATGGCA \\
\hline HGF & GCTATCGGGGTAAAGACCTACA & CGTAGCGTACCTCTGGATTGC \\
\hline bFGF & AGAAGAGCGACCCTCACATCA & CGGTTAGCACACACTCCTTTG \\
\hline
\end{tabular}

\section{Statistical analyses}

All quantitative results are presented as means \pm SDs. Statistical comparisons were performed using a Student's $t$ test in three independent experiments. GraphPad Prism version 7.0 software (GraphPad Inc., La Jolla, CA, USA) was used for data analysis. Statistical significance was set at $p<0.05$.

\section{Results}

\section{ADSCs displayed multipotent differentiation and} expressed stem cell markers

The multipotency of ADSCs was examined by osteogenic, chondrogenic, and adipogenic differentiation assays. ADSCs were cultured and induced with osteogenic medium for 4 weeks and stained with Alizarin red to confirm the presence of calcium deposits (Fig. 2A). ADSCs were induced with chondrogenic medium for 4 weeks, and sections of cartilage balls were stained with Alcian blue (Fig. 2B). ADSCs were induced with adipogenic medium for 4 weeks and developed an adipogenic phenotype, which showed the presence of lipid droplets in the cells by oil red $\mathrm{O}$ staining (Fig. 2C). The ADSCs were characterized using mesenchymal stem cell surface markers as CD29+ (96.12\%), CD31+ (0.17\%), CD45+ (0.77\%), CD90+ (96.79\%), CD105+ (96.21\%), and CD44+ (98.84\%) (Fig. 2D-I) [22]. These results revealed that the ADSCs isolated from the human adipose tissue demonstrated typical ADSC characteristics.

\section{ADSC-CM promoted DFSP cell proliferation}

The CCK-8 assay was used to evaluate the effect of ADSC-CM on DFSP cell proliferation. As shown in Fig. 3, ADSC-CM significantly promoted DFSP cell proliferation at days 5 and 7 compared with that in the control condition $(p<0.05)$. There were no significant differences in cell proliferation rates between the experimental and control conditions during the first 3 days.

\section{ADSC-CM or ADSCs promoted DFSP cell migration}

We evaluated the ability of ADSCs to affect DFSP cell migration. First, as shown in Fig. 4A, the ability of ADSC-CM to affect DFSP cell migration was tested using a scratch wound model in which DFSP cells were treated with ADSC-CM (experimental), DMEM/F12+10\% FBS (positive control), or DMEM/F12 SF (negative control). At 6 h, DFSP cells of the negative control (DMEM/F12 SF) group migrated to $9.3 \pm 1.5 \%$ of the scratched area, whereas the ADSC-CM-treated DFSP cells migrated to $15.9 \pm 2.3 \%$ of the area $(p<0.05$, Fig. $4 \mathrm{~B})$. At $12 \mathrm{~h}$, the DFSP cells of the negative control group had migrated to $8.7 \pm 0.1 \%$ of the scratched area, whereas the ADSC-CM-treated DFSP cells migrated $17.5 \pm 4.7 \%$ of the area $(p<0.05$, Fig. 4 C). At $24 \mathrm{~h}$, the DFSP cells from the negative control group had migrated to $13.3 \pm 2.8 \%$ of the scratched area, whereas the ADSC-CM-treated DFSP cells had migrated $47.4 \pm 4.4 \%$ of the area $(p<0.05$, Fig. $4 \mathrm{D})$. These results showed that treatment with ADSC-CM significantly promoted the migration of DFSP cells at 6, 12, and 24 h (1.71-, 2.01-, and 3.56-fold, respectively) compared with the negative control (DMEM/ F12 SF).

Next, we tested if the presence of ADSCs in the basal compartment could induce a stronger response than that generated by ADSC-CM in a Transwell system (Fig. 5B). As shown in Fig. 5A, the effect of ADSCs on DFSPmigrated cell counts was tested using the Transwell system, in which DFSP cells were incubated with ADSCs (experimental), DMEM/F12+10\% FBS (positive control), or DMEM/F12 SF (negative control). At $12 \mathrm{~h}, 4.7 \pm 1.2$ DFSP cells had migrated in the negative control group, whereas $52.5 \pm 2.4$ cells had migrated in the experimental group $(p<0.05$, Fig. 5 C). At 24 h, $6.2 \pm 2.2$ cells showed migration in the negative control group, whereas the number was $38.2 \pm 12.6$ cells in the experimental group $(p<0.05$, Fig. 5D). The results showed that treatment with ADSCs more significantly promoted the migration of DFSP cells at 12 and $24 \mathrm{~h}$ time points (11.17- and 6.16-fold, respectively) compared with that observed in negative control conditions (DMEM/F12 SF).

\section{ADSC-CM enhanced DFSP cell invasion}

The invasive properties of DFSP cells allow them to digest the Matrigel matrix, a basement membrane preparation extracted from the Engelbreth-Holm-Swarm mouse sarcoma. As shown in Fig. 6A, the effect of ADSC-CM on DFSPinvaded cell counts was tested using a Transwell system with pre-coated Matrigel; DFSP cells were treated with DMEM/F12+10\%FBS (positive control), DMEM/F12 SF (negative control), or ADSC-CM (experimental). At $36 \mathrm{~h}$, 

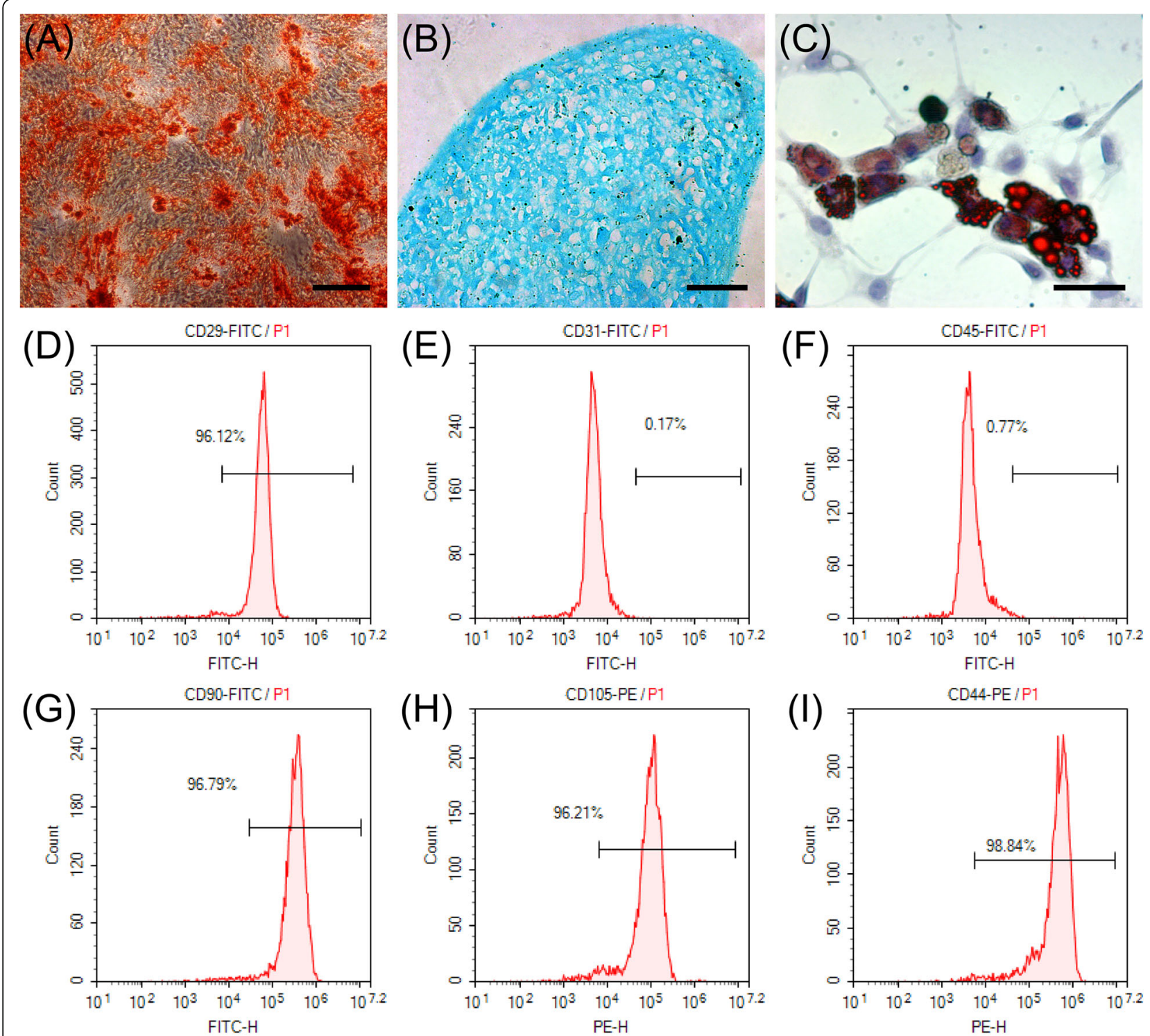

Fig. 2 Characterization of human adipose-derived stem cells (ADSCs). The differentiation into A Alizarin Red-stained osteocytes (scale bar=100 $\mu \mathrm{m}), \mathbf{B}$ Alcian blue-stained chondrocytes (scale bar $=50 \mu \mathrm{m}$ ), and $\mathbf{C}$ oil red O-stained adipocytes (scale bar=50 $\mu \mathrm{m})$ was induced. Flow cytometric analysis of ADSCs: ADSCs expressed D CD29+ (96.12\%), E CD31+ (0.17\%), F CD45+ (0.77\%), G CD90+ (96.79\%) marked with fluorescein isothiocyanate (FITC), H CD105+(96.21\%), and I CD44+(98.84\%) marked with phycoerythrin (PE)

$0.7 \pm 0.8$ cells in the negative control group had invaded the lower surface, whereas in the experimental group, $4.2 \pm 1.9$ cells showed invasion $(p<0.05$, Fig. $6 \mathrm{C})$. The results showed that treatment with ADSC-CM could promote the invasion of DFSP cells at $36 \mathrm{~h}$ (7-fold) more significantly than the negative control could (DMEM/F12 SF).

\section{Co-cultured DFSP/ADSC-CM enhanced angiogenic properties in vitro}

To evaluate the effect of proteins secreted by ADSCs, DFSP cells, and co-cultured DFSP cells and ADSCs on angiogenesis, HUVECs were incubated with different CMs (ADSC-CM, DFSP-CM, and co-cultured DFSP/ ADSC-CM) that led to the formation of tubular networks. These were visible through inspection under an inverted light microscope after $4 \mathrm{~h}$ of incubation (Fig. $7 \mathrm{~A}, \mathrm{~B})$. We observed a significant increase in the number of meshes, total tube length, and total branch length of tubular networks formed by HUVECs cultured with cocultured DFSP/ADSC-CM compared with those observed in the control groups (ADSC-CM or DFSP-CM; $p<0.05$, Fig. 7C-E). 


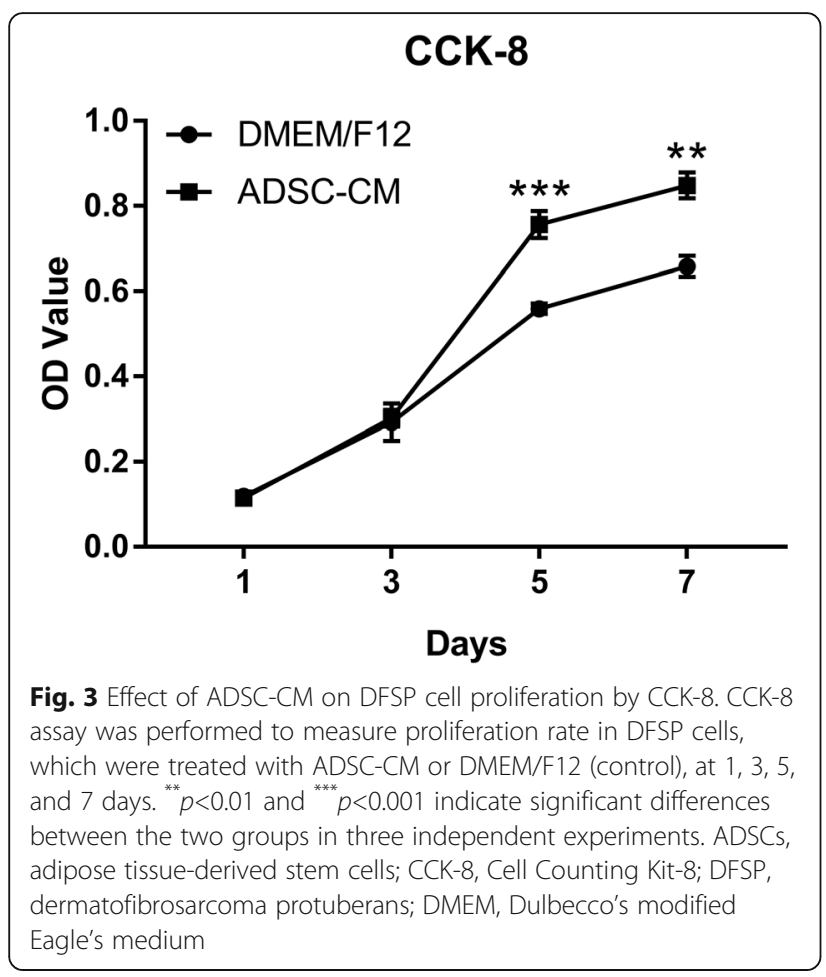

ADSCs increased the expression of DFSP-related genes and the protein levels

After DFSP cells were cultured with ADSCs using the Transwell system for $24 \mathrm{~h}$, the mRNA levels of PDGFRB and COL1A1 in DFSP cells showed 1.4-fold and 1.5-fold increases, respectively, compared with the levels in mono-cultured DFSP cells $(p<0.05$, Fig. 8 A, B). After 48 $\mathrm{h}$, in the co-cultured cells, the protein levels of PDGFRB were increased moderately and the protein levels of COL1A1 were increased significantly compared with those in the mono-cultured DFSP cells (Fig. 8C-E). Similar trends were observed in the qRT-PCR and Western blotting experiments.

\section{ADSCs increase growth factor gene expression in DFSP cells and growth factor secretion in the co-cultured DFSP microenvironment}

After DFSP cells were cultured with ADSCs using the Transwell system for $24 \mathrm{~h}$, the mRNA expression of the proangiogenic genes VEGF, HGF, and $b F G F$ in DFSP cells was elevated 1.32-fold, 1.2-fold, and 1.4-fold, respectively, compared with those in the mono-cultured DFSP cells $(p<0.05$, Fig. 9A-C). After $48 \mathrm{~h}$, the levels of VEGF, HGF, and bFGF secretion in the collected supernatants from the co-culture (experimental group) were

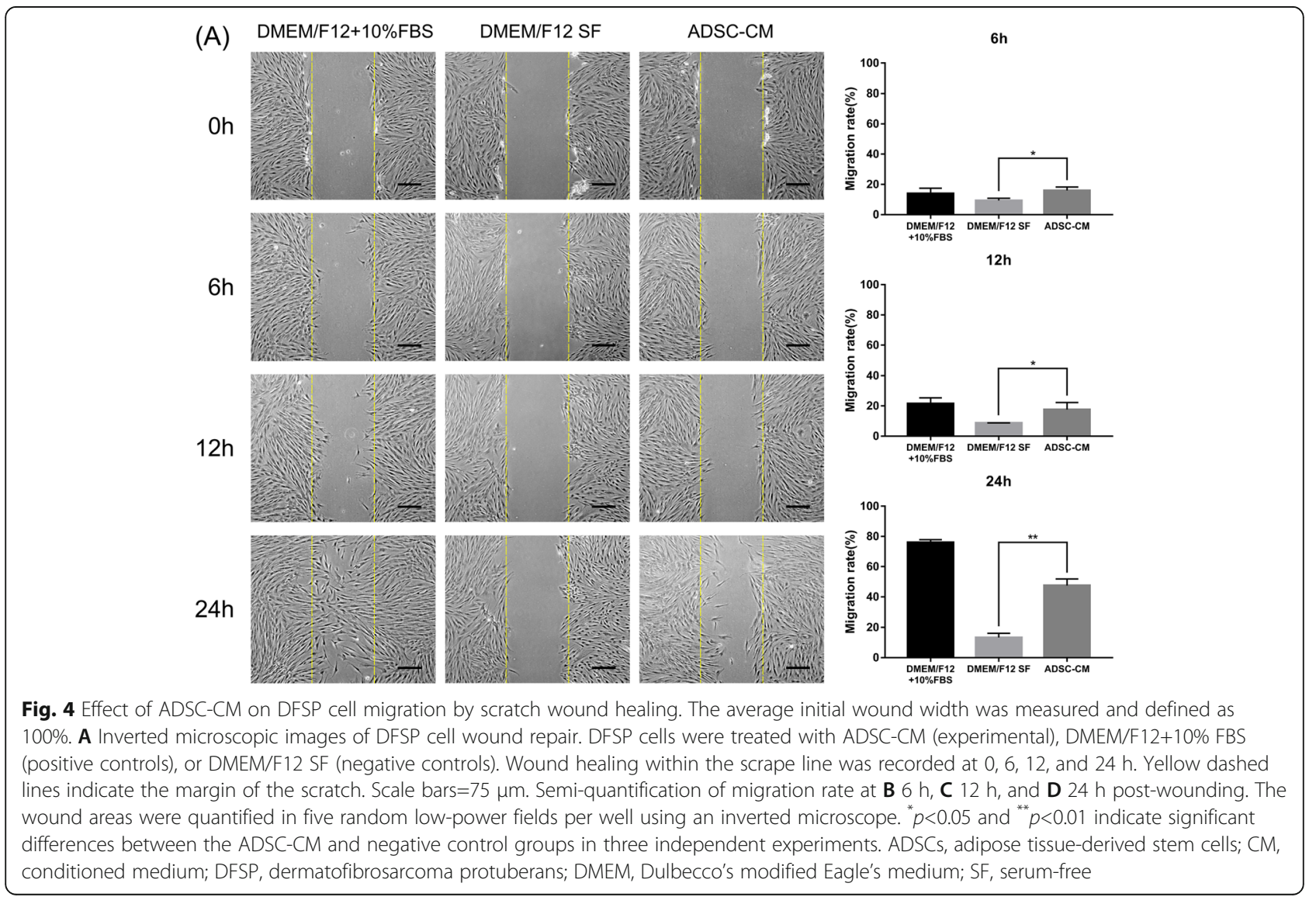



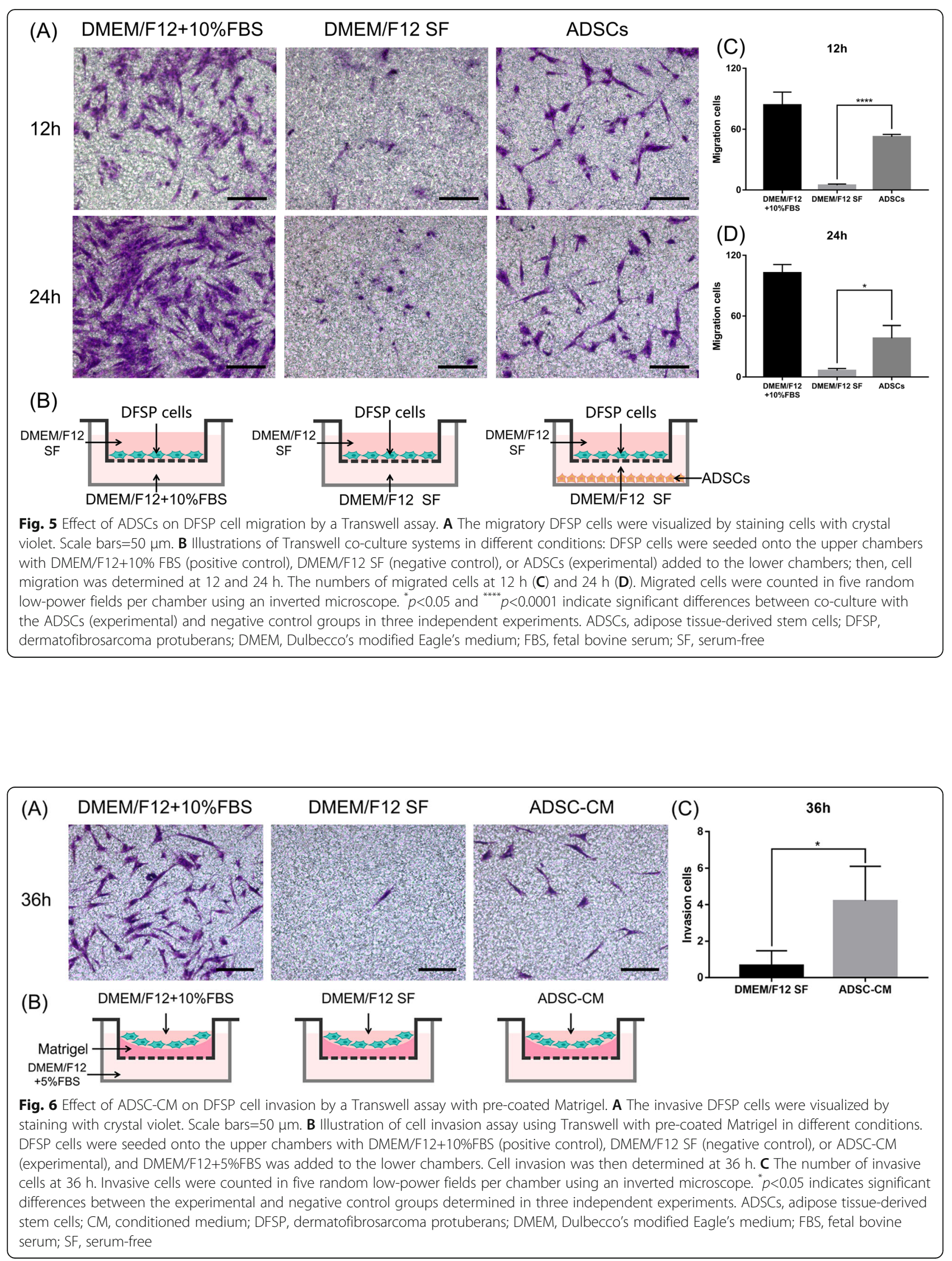


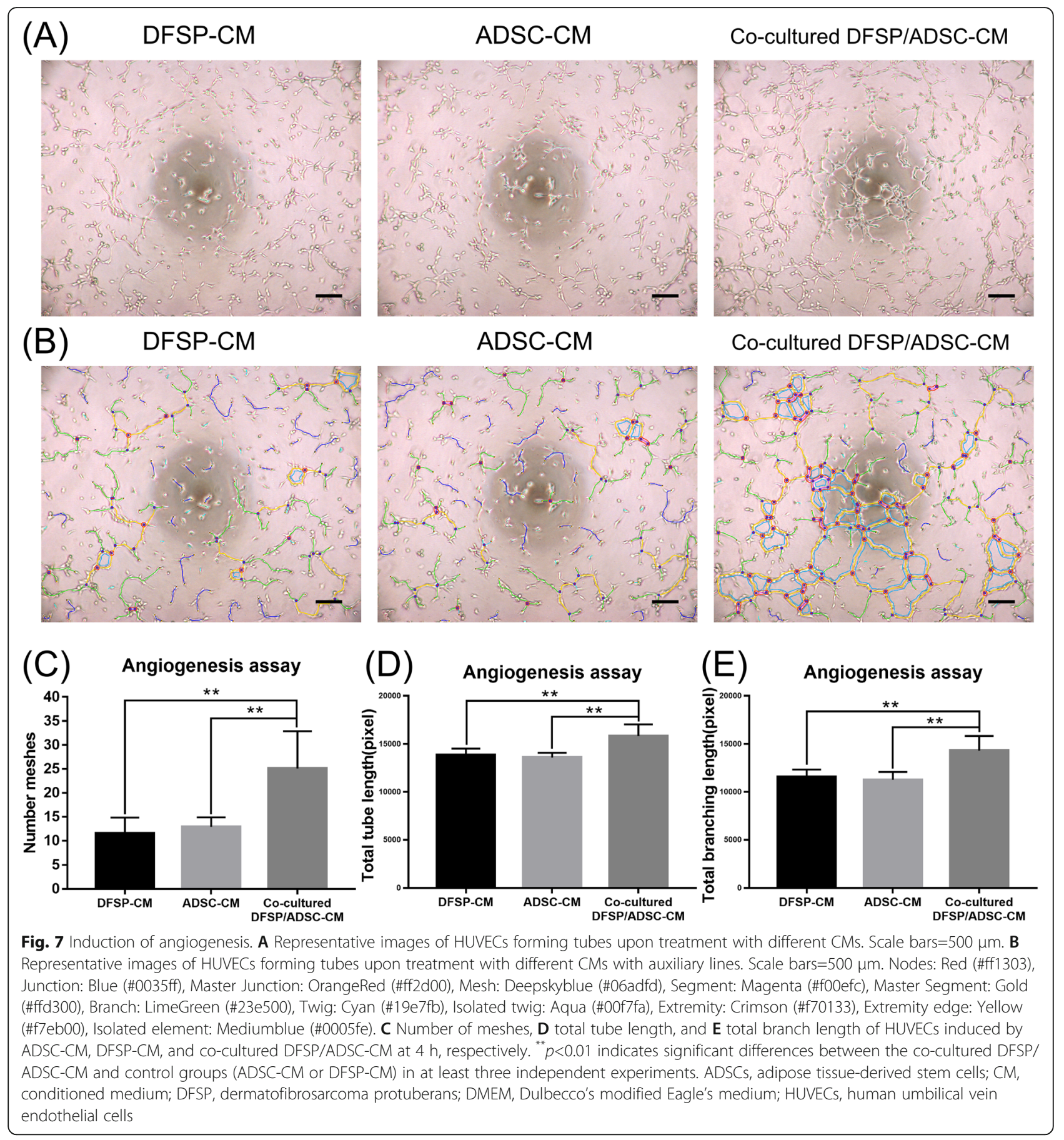

significantly higher compared with those in the supernatants of the mono-cultured DFSP cells (control group). The concentration of VEGF in the experimental group was $98.0 \pm 3.5 \mathrm{pg} / \mathrm{mL}$, whereas it was $64.2 \pm 3.9 \mathrm{pg} / \mathrm{mL}$ in the control group ( $p<0.0001$, Fig. 9D). The concentration of HGF in the experimental group was $287.4 \pm 14.1 \mathrm{pg} /$ $\mathrm{mL}$, whereas it was $202.5 \pm 12.0 \mathrm{pg} / \mathrm{mL}$ in the control group ( $p<0.01$, Fig. 9E). The concentration of bFGF in the experimental group was $31.6 \pm 6.3 \mathrm{pg} / \mathrm{mL}$, whereas it was $19.6 \pm 1.8 \mathrm{pg} / \mathrm{mL}$ in the control group $(p<0.05$, Fig. 9F).

\section{Discussion}

The regenerative therapeutic efficacy of cell-assisted lipotransfer is dependent on the presence of ADSCs, although the stromal microenvironment and hormonal secretions of the adipose tissue are possibly involved in tumor progression [37]. There are only a few studies 

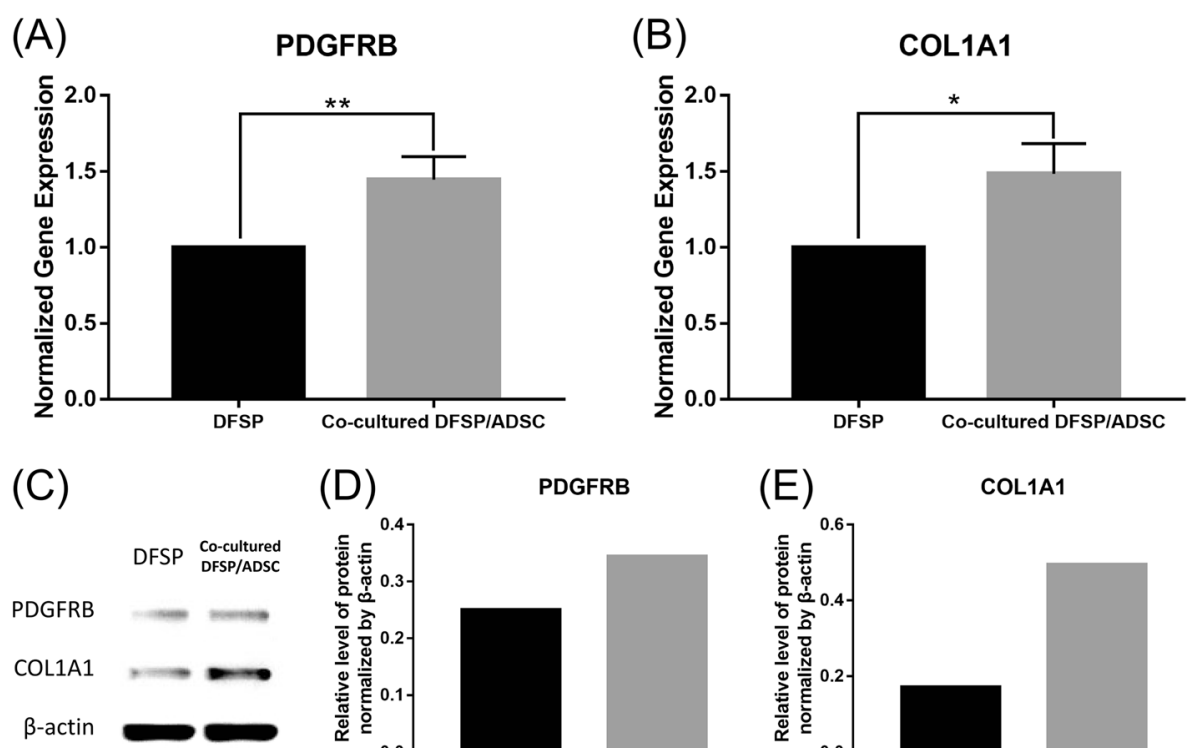

(D)

PDGFRB
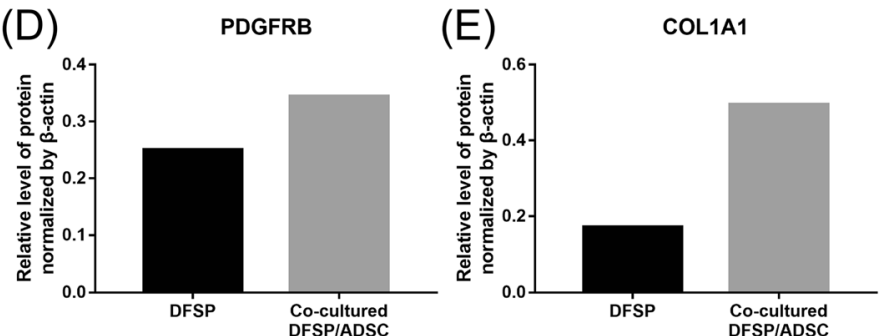

Fig. 8 Effect of ADSCS on DFSP-related gene and protein expression in DFSP cells. A Beta-type platelet-derived growth factor receptor (PDGFRB) and $\mathbf{B}$ collagen type I alpha 1 chain (COL1A1) gene expression levels in DFSP cells in a mono-culture (control group) or a co-culture with ADSCs (experimental group). Data were normalized to the level of the control group. Each group was tested in triplicate. Results are shown as means \pm standard deviations. ${ }^{*} p<$ 0.05 and ${ }^{* *} p<0.01$ indicate significant differences in relation to the control group. The protein levels of PDGFRB and COL1A1 (C-E) were measured by Western blotting in DFSP cells in the control and experimental groups. ADSCs, adipose tissue-derived stem cells; DFSP, dermatofibrosarcoma protuberans
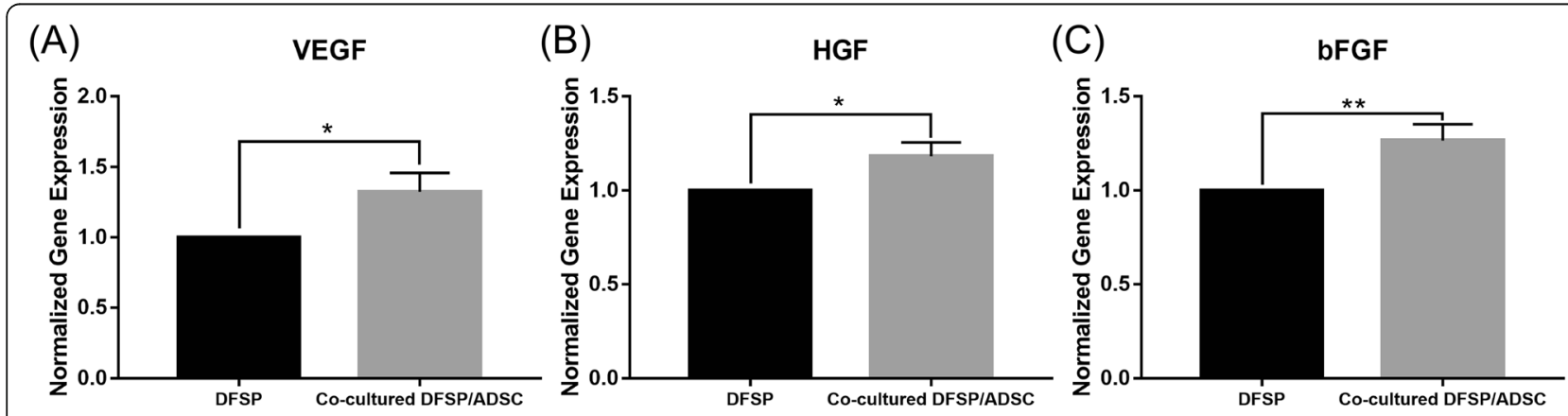

(D)

(E)

HGF

$(\mathrm{F})$ bFGF
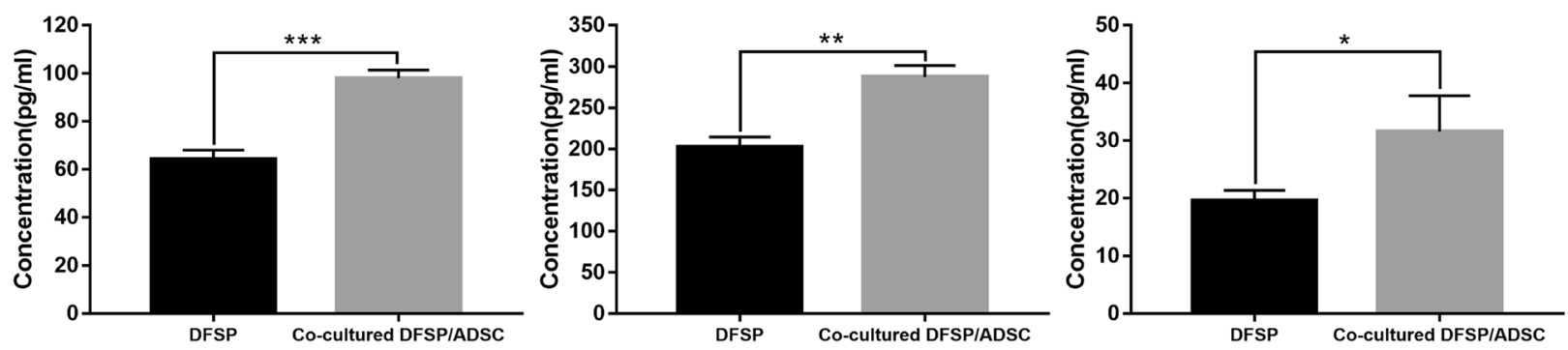

Fig. 9 Effect of ADSCS on growth factor gene expression and protein secretion in DFSP cells and microenvironment. A Vascular endothelial growth factor (VEGF), B hepatocyte growth factor (HGF), and C basic fibroblast growth factor (bFGF) gene expression levels in DFSP cells in a monoculture (control group) or co-culture with ADSCS (experimental group). Data are normalized to the level of the control group. Levels of $\mathbf{D}$ VEGF, E HGF, and $\mathbf{F}$ bFGF secretion in the supernatants of DFSP-mono-culture (control group) and DFSP-ADSC-co-culture (experimental group) at $48 \mathrm{~h}$ were detected by ELISA. ${ }^{*} p<0.05,{ }^{* *} p<0.01$, and ${ }^{* * *} p<0.001$ indicate significant differences in relation to the control group in three independent experiments. ADSCs, adipose tissue-derived stem cells; DFSP, dermatofibrosarcoma protuberans; ELISA, enzyme-linked immunosorbent assay 
assessing the oncological outcomes of the interaction between ADSCs and malignant neoplasms of mesenchymal origin [17]. None of these studies have guided the therapeutic application of ADSCs in DFSP.

This is the first study to demonstrate the effects of human ADSCs on human DFSP cells by co-culture in vitro; we found that ADSCs promoted the proliferation, migration, invasion, and angiogenic properties of DFSP cells. Furthermore, in DFSP cells, changes in $P D G F R B$ and COL1A1 gene expression and protein levels were observed. Additionally, a remarkable change in the secreted protein levels of VEGF, $b F G F$, and $H G F$ in the co-cultured microenvironment was observed, which plays an important role in mediating the tumorpromoting effect. These changes strongly point toward serious adverse biological consequences that may arise in the in vivo co-presence of ADSCs and DFSP cells.

Our results clearly show an increased proliferation rate in DFSP cells after co-culture with ADSC-CM. These changes suggest that direct physical contact between ADSCs and DFSP cells is not required for ADSCs to regulate the proliferation of DFSP cells, and the major mechanism underlying this may be related to their paracrine activity in the microenvironment. In sarcoma, a recent report has also shown that ADSCs trigger osteosarcoma cell proliferation in vitro, and these results were both observed in the co-culture and CM groups [27]. Meanwhile, ADSCs facilitate cell proliferation in solid malignancies of nonmesenchymal origin, including tumors of the endometrium, breast, ovary, gastric area, lung, melanoma, pancreas, and thyroid [3]. However, exposure of glioma cells to $\mathrm{CM}$ for $24 \mathrm{~h}$ and $48 \mathrm{~h}$ did not alter cell proliferation [25]. Furthermore, previous studies have reported that ADSCs inhibit prostate cancer cell proliferation-inducing apoptosis [38], hepatocellular carcinoma cell proliferation and division [39], and pancreatic ductal adenocarcinoma cell proliferation by altering cell cycle progression [40]. Therefore, until recently, there is no consensus in the literature regarding the effect of ADSCs on tumor cell proliferation due to the differences in cell source of cancer, model of cancer tested, or species studied [25].

Next, we observed that ADSC-CM and ADSCs could boost the migration of DFSP cells through indirect coculture. These results are consistent with those of previous reports on the increased migration of skin tumor cells, such as malignant melanoma cells [26], squamous cell carcinoma cells [12], and non-skin tumor cells, such as breast cancer cells (line MCF7) [41] and gastric cancer cells [42]. Even in the absence of the physical presence of ADSCs, the secretome of ADSCs can promote DFSP cell migration. Interestingly, this effect was more prominent in the co-culture Transwell system, where DFSP cells shared the same medium with ADSCs without direct physical contact. This can be explained by the fact that the crosstalk between different cells together in the same microenvironment could enhance action [43].

Increased migration, a key in the process of cellular invasiveness, is involved in the degradation of the basement membrane and extracellular matrix [44]. The cell invasion assay demonstrated that ADSC-CM could stimulate DFSP cells to degrade the matrix promptly and to invade through the basement membrane. In other words, the invasiveness of DFSP cells was increased. This is consistent with the findings of previous studies on the effect of ADSCs on the metastatic ability of cancer cells, including all tumors of mesenchymal origin [27] and non-mesenchymal origin [3].

Subsequently, the co-cultured DFSP/ADSC-CM facilitated the formation of more tubular networks in HUVECs than did ADSC-CM or DFSP-CM alone. This suggests that the interaction between DFSP cells and ADSCs can regulate paracrine signaling in the TME to enhance angiogenesis, which is essential in the pathogenesis of rapid growth and metastasis in solid tumors [45]. Clearly, ADSCs have powerful angiogenic and vasculogenic capabilities in the development and progression of a wide variety of cancers, including malignant melanoma cells [26], squamous cell carcinoma cells [12], breast cancer cells [46], lung adenocarcinoma cells [47], and glioblastoma [48].

Finally, to confirm the possible mechanisms by which ADSCs enhance the malignant properties of DFSP cells, the main features of DFSP in the co-cultured microenvironment were evaluated. The expression of PDGFRB and COL1A1 in DFSP cells co-cultured with ADSCs was found to be higher at the mRNA and protein levels compared with those in controls, which was not surprising.

Soft tissue sarcomas have been suggested to contain PDGF autocrine loops. Co-expression of ligands and receptors has been observed in clinical samples of fibroblast-derived tumors, such as DFSP [49]. DFSP presents with specific cytogenetic features, such as reciprocal translocations $\mathrm{t}(17 ; 22)$ (q22;q13.1) or supernumerary ring chromosomes derived from $t(17 ; 22)[50,51]$. The result of this rearrangement is the upregulation of COL1A1-PDGFB fusion proteins that are processed to form mature PDGFB and then to activate PDGFRB [52] to form an autocrine loop [53], rendering tumor cell proliferation and survival dependent on PDGFRB signaling [54]. Notably, PDGFB confers a tumorigenic phenotype to human tumor cells bearing PDGFBR but not to cells devoid of receptors [55]. As is well-known, PDGFB can act on a variety of cells by stimulating mitogenicity and chemotaxis [56]. PDGFB can also upregulate the expression of its own receptor (PDGFRB) on capillary endothelial cells to stimulate angiogenesis [57] through its ability to recruit pericytes and to improve the development of vascular smooth muscle cells [58]. 
Considering this, based on the high expression of PDGFRB in DFSP cells, ADSCs further promoted DFSP cells to express higher levels of PDGFRB, which amplified the effectiveness of PDGFRB signaling. These findings were consistent with the findings observed in breast cancer cells reported in the literature, with data suggesting that tumor cell-derived PDGFB/PDGFRB signaling pathway is an important factor in governing the microenvironment interaction between tumor cells and local tissue-resident stem cells [46].

Furthermore, in DFSP, the processing of the chimeric COL1A1-PDGFB protein into PDGFB dimers also results in the production of significant quantities of the COL1A1 chains. These would be combined as trimers with COL1A2 chains and processed into mature collagen fibers in the extracellular medium [59]. Through collagen bundles, the neoplasm can invade laterally and deeply along the connective tissue septae to proliferate [15]. Thus, ADSCs could promote DFSP migration and invasion via further increasing the COL1A1 expression level in DFSP cells. Recent studies have also found that COL1A1 appears to exert an oncogenic effect, which promotes tumor migration by rearranging the actin cytoskeleton and regulating the planar polarity of the cells [60, 61]. Moreover, increased COL1A1 levels were associated with poor survival [62].

Interestingly, according to studies, in keloid, one of the benign skin tumors [63], ADSCs could reduce the expression of COL1A1 in keloid fibroblasts and deposition of collagen in keloid tissue ex vivo. Currently, the reasons and mechanisms for these differential impacts of ADSCs on benign and malignant tumors are unclear. Thus, further studies should be conducted.

Meanwhile, more proangiogenic factors such as VEGF, HGF, and bFGF were detected in co-cultured DFSP/ ADSC supernatant than in mono-cultured DFSPsupernatant. Furthermore, the expression of VEGF, HGF, and bFGF in DFSP cells co-cultured with ADSCs was found to be increased. In other words, ADSCs not only autocrined VEGF, HGF, and bFGF but also promoted the expression of VEGF, HGF, and bFGF in DFSP cells. This suggests that angiogenic efficiency was more greatly enhanced in co-culture TME. These findings are consistent with those of the previous literature [3]. Within a variety of tumor types and pathways, ADSCs produce numerous growth factors, including VEGF, HGF, and bFGF [64], which lead to increased vascularization [3]. It is well known that VEGF, HGF, and bFGF are potent proangiogenic factors, which all have been independently implicated in angiogenesis [65-67]. Meanwhile, VEGF and bFGF have a potent synergistic effect on the induction of angiogenesis in vitro [68]. HGF has been shown to increase the expression of VEGF to initiate angiogenesis [69] and to act in synergy with VEGF to amplify angiogenesis [70, 71]. Studies have also shown that ADSCs in the breast tissue can promote invasion of breast cancer cells via a VEGF-A-dependent manner [72], and ADSCs may favor breast cancer recurrence via HGF/c-Met signaling [73].

Taken together, the co-culture of ADSCs and DFSP cells led to considerable enhancement in malignant properties of DFSP cells in vitro. This points to a potentially increased oncological risk in vivo, which should not be neglected when considering the clinical use of fat, stem cell-enriched, and isolated ADSCs in patients with DFSP or residual DFSP cells.

\section{Conclusion}

In the current study, we first explored the interactions between ADSCs and DFSP cells using an in vitro coculture model to understand the effects of ADSCs on tumor development. This report provides evidence that ADSCs significantly affect multiple malignant features, such as gene expression, protein secretion, proliferation, migration, invasion, and angiogenesis, of DFSP cells in vitro. Therefore, ADSCs may strongly increase the risk of DFSP tumor development in vivo if administered near malignant tumor cells. Our results need to be considered when discussing the safety of ADSC-based therapies for patients with DFSP or residual DFSP cells. The informed consent forms for such procedures should mention the increased risk of cancer and relapse and the possibility of faster growth and dissemination of a preexisting cancer [74]. Additionally, it appears crucial to rigorously screen all patients before the injection of adipose derivatives such as fat, stromal vascular fraction, or isolated ADSCs in adjacent tissues to avoid potential colocalization of ADSCs and DFSP cells.

\section{Abbreviations \\ ADSCs: Adipose tissue-derived stem cells; bFGF: Basic fibroblast growth factor; CAFs: Cancer-associated fibroblasts; CCK-8: Cell Counting Kit-8; CM: Conditioned medium; COL1A1: Collagen type I alpha 1 chain; DFSP: Dermatofibrosarcoma protuberans; DMEM: Dulbecco's modified Eagle's medium; ELISA: Enzyme-linked immunosorbent assay; FBS: Fetal bovine serum; HGF: Hepatocyte growth factor; hMSCs: Human mesenchymal stem/ stromal cells; HUVECs: Human umbilical vein endothelial cells; MMPs: Matrix metalloproteinases; PBS: Phosphate-buffered saline; PDGFRB: Beta-type platelet-derived growth factor receptor; qRT-PCR: Real-time quantitative real- time polymerase chain reaction; SF: Serum-free; TME: Tumor microenvironment; VEGF: Vascular endothelial growth factor}

\section{Acknowledgements}

This study was financially supported by the National Natural Science Foundation of China and Shanghai Municipal Key Clinical Specialty. We like to thank our group members.

\section{Authors' contributions}

YZQ and ZZ planned and performed the experiments and completed the manuscript. YZQ and ZFX revised the manuscript. DFX, WYM, and WXX helped $Y Z Q$ to perform experiments. YJ and LXS supervised the study. YZQ, $L F$, and SD designed the study. The authors discussed and approved the manuscript. 


\section{Funding}

This study was supported by grants from the National Natural Science Foundation of China $(81871576 ; 81701901 ; 81801946)$ and Shanghai Municipal Key Clinical Specialty (shslczdzk00901).

\section{Availability of data and materials}

All data generated or analyzed during this study are included in this published article and its supplementary information files.

\section{Declarations}

\section{Ethics approval and consent to participate}

All these experiments were approved by the Shanghai Jiao Tong University of Medicine ethics committee, and all patients consented to the respective use of their tissues (Approval Number: HJYKLS[2018]239).

\section{Consent for publication}

Not applicable.

\section{Competing interests}

The authors declare that they have no competing interests.

\section{Author details}

${ }^{1}$ Department of Plastic and Reconstructive Surgery, Shanghai Ninth People's Hospital, Shanghai Jiao Tong University School of Medicine, Shanghai 200011, China. ${ }^{2}$ Shanghai Key Lab of Tissue Engineering, Shanghai Ninth People's Hospital, Shanghai Jiao Tong University School of Medicine, Shanghai 200011, China. ${ }^{3}$ Department of Oral and Cranio-maxillofacial Surgery, Shanghai Ninth People's Hospital, College of Stomatology, Shanghai Jiaotong University School of Medicine, Shanghai 200011, China.

Received: 28 April 2021 Accepted: 11 July 2021

Published online: 06 August 2021

\section{References}

1. Matthias I, Jody V. Recio Boiles Alejandro et al. Two sides of the same coin: stem cells in cancer and regenerative medicine. FASEB J. 2014;28(7):274861. https://doi.org/10.1096/fj.13-244640.

2. De Francesco F, Giulia R, D'Andrea F, et al. Human adipose stem cells: from bench to bedside. Tissue Eng Part B Rev. 2015;21:572-84. https://doi.org/1 0.1089/ten.TEB.2014.0608

3. Freese Kyle E, Lauren K, Edwards Robert P, et al. Adipose-derived stems cells and their role in human cancer development, growth, progression, and metastasis: a systematic review. Cancer Res. 2015;75:1161-8. https://doi. org/10.1158/0008-5472.CAN-14-2744.

4. Kapur Sahil K, Katz AJ. Review of the adipose derived stem cell secretome. Biochimie. 2013:95(12):2222-8. https://doi.org/10.1016/j.biochi.2013.06.001.

5. Alperovich $M$, Lee ZH, Friedlander PL, et al. Adipose stem cell therapy in cancer reconstruction: a critical review. Ann Plast Surg. 2014;73. https://doi. org/10.1097/SAP.0000000000000283.

6. Wen-Chia H, Lu I-L, Wen-Hsuan C, et al. Tumortropic adipose-derived stem cells carrying smart nanotherapeutics for targeted delivery and dualmodality therapy of orthotopic glioblastoma. J Control Release. 2017;254: 119-30. https://doi.org/10.1016/j.jconrel.2017.03.035.

7. Dumitru-Daniel H, Luminita L, Ecaterina R, et al. Human adipose-derived stem cells loaded with drug-coated magnetic nanoparticles for in-vitro tumor cells targeting. Mater Sci Eng C Mater Biol Appl. 2019;94:666-76. https://doi.org/10.1016/j.msec.2018.10.019.

8. Donnenberg Vera S, Ludovic Z, Peter RJ, et al. Regenerative therapy after cancer: what are the risks? Tissue Eng Part B Rev. 2010;16(6):567-75. https:// doi.org/10.1089/ten.TEB.2010.0352.

9. Lin G, Yang R, Lia B, et al. Effects of transplantation of adipose tissue-derived stem cells on prostate tumor. Prostate. 2010;70(10):1066-73. https://doi. org/10.1002/pros.21140.

10. Raghu K, Michael Z. Fibroblasts in cancer. Nat Rev Cancer. 2006;6(5):392401. https://doi.org/10.1038/nrc1877.

11. Constantin J, Eckhard A, Gabriel W, et al. Adipose tissue derived stem cells differentiate into carcinoma-associated fibroblast-like cells under the influence of tumor derived factors. Cell Oncol. 2011;34:55-67. https://doi. org/10.1007/s13402-011-0012-1.
12. Eva K, Felix G, Fabian P, et al. Alterations of gene expression and protein synthesis in co-cultured adipose tissue-derived stem cells and squamous cell-carcinoma cells: consequences for clinical applications. Stem Cell Res Ther. 2014;5:65. https://doi.org/10.1186/scrt454.

13. Panta R, Fletcher Christopher DM, Devesa Susan S, et al. Cutaneous soft tissue sarcoma incidence patterns in the U.S.: an analysis of 12,114 cases. Cancer. 2008;113:616-27. https://doi.org/10.1002/cncr.23571.

14. Bichakjian CK. Dermatofibrosarcoma protuberans: clinical practice guidelines in oncology. J Natl Compr Canc Netw. 2019;2(1):MS-2-3.

15. Ratner D, Thomas CO, Johnson TM, Sondak VK, Hamilton TA, Nelson BR, et al. Mohs micrographic surgery for the treatment of dermatofibrosarcoma protuberans. Results of a multiinstitutional series with an analysis of the extent of microscopic spread. J. Am. Acad. Dermatol. 1997;37(4):600-13. https://doi.org/10.1016/s0190-9622(97)70179-8.

16. Criscione Vincent D, Weinstock Martin A. Descriptive epidemiology of dermatofibrosarcoma protuberans in the United States, 1973 to 2002. J Am Acad Dermatol. 2007;56(6):968-73. https://doi.org/10.1016/j.jaad.2006.09.006.

17. Angela $P$, Egidio R, Giuseppe $M$, et al. Autologous fat grafting after sarcoma surgery: evaluation of oncological safety. J Plast Reconstr Aesthet Surg. 2018;71(12):1723-9. https://doi.org/10.1016/j.bjps.2018.07.028.

18. Wang $X, M a Y, G a o ~ Z$, et al. Human adipose-derived stem cells inhibit bioactivity of keloid fibroblasts. Stem Cell Res Ther. 2018;9:40. https://doi. org/10.1186/s13287-018-0786-4.

19. Jiang $Y$, Jahagirdar BN, Reinhardt RL, Schwartz RE, Keene CD, Ortiz-Gonzalez $X R$, et al. Pluripotency of mesenchymal stem cells derived from adult marrow. Nature. 2002;418(6893):41-9. https://doi.org/10.1038/nature00870.

20. Halimeh M, Ezzatollah F, Raheleh F, et al. L-carnitine significantly decreased aging of rat adipose tissue-derived mesenchymal stem cells. Vet Res Commun. 2017;41(1):41-7. https://doi.org/10.1007/s11259-016-9670-9.

21. Wang $Y$, Wang $X$, Xianyu Z, et al. Suppressive effect mediated by human adipose-derived stem cells on T cells involves the activation of JNK. Int J Mol Med. 2019:43:177-84. https://doi.org/10.3892/ijmm.2018.3953.

22. Philippe B, Bunnell Bruce A, Louis C, et al. Stromal cells from the adipose tissue-derived stromal vascular fraction and culture expanded adipose tissue-derived stromal/stem cells: a joint statement of the International Federation for Adipose Therapeutics and Science (IFATS) and the International Society for Cellular Therapy (ISCT). Cytotherapy. 2013;15:641-8. https://doi.org/10.1016/j.jcyt.2013.02.006.

23. Rieko O, Fusako K, Zhiwei Q, et al. Establishment of novel patient-derived models of dermatofibrosarcoma protuberans: two cell lines, NCC-DFSP1-C1 and NCC-DFSP2-C1. In Vitro Cell Dev Biol Anim. 2019;55(1):62-73. https:// doi.org/10.1007/s11626-018-0305-z.

24. Bonish BK, Foreman KE, Gutierrez-Steil C, Nickoloff BJ. Phenotype and proliferation characteristics of cultured spindle-shaped cells obtained from normal human skin and lesions of dermatofibroma, Kaposi's sarcoma, and dermatofibrosarcoma protuberans: a comparison with fibroblast and endothelial cells of the dermis. J Dermatol Sci. 1997;16(1):52-8. https://doi. org/10.1016/s0923-1811(97)00621-x.

25. Iser Isabele C, Ceschini Stefanie M, Onzi Giovana R, et al. Conditioned medium from adipose-derived stem cells (ADSCs) promotes epithelial-tomesenchymal-like transition (EMT-Like) in glioma cells in vitro. Mol Neurobiol. 2016;53(10):7184-99. https://doi.org/10.1007/s12035-015-9585-4.

26. Fabian $\mathrm{P}$, Uwe L, Stefanie $\mathrm{S}$, et al. Impact of human adipose tissue-derived stem cells on malignant melanoma cells in an in vitro co-culture model. Stem Cell Rev Rep. 2018;14(1):125-40. https://doi.org/10.1007/s12015-017-9772-y.

27. Wang $Y$, Yijing C, Bin Y, et al. Adipose-derived mesenchymal stem cells promote osteosarcoma proliferation and metastasis by activating the STAT3 pathway. Oncotarget. 2017;8:23803-16. https://doi.org/10.18632/oncota rget.15866.

28. Liang C-C, Park AY, Guan J-L. In vitro scratch assay: a convenient and inexpensive method for analysis of cell migration in vitro. Nat Protoc. 2007; 2(2):329-33. https://doi.org/10.1038/nprot.2007.30.

29. Zhu Z, Yuan Z-Q, Huang C, et al. Pre-culture of adipose-derived stem cells and heterologous acellular dermal matrix: paracrine functions promote post-implantation neovascularization and attenuate inflammatory response. Biomed Mater. 2019;14:035002. https://doi.org/10.1088/1748-605X/ab0355.

30. Lourdes PM. Tube formation: an in vitro matrigel angiogenesis assay. Methods Mol Biol. 2009;467:183-8. https://doi.org/10.1007/978-1-59745-241-0_10.

31. Ezzatollah F, Raheleh F, Sara J, et al. L-carnitine extends the telomere length of the cardiac differentiated CD117-expressing stem cells. Tissue Cell. 2020; 67:101429. https://doi.org/10.1016/j.tice.2020.101429. 
32. Ezzatollah F, Raheleh F, Ilja V, et al. Cardiac differentiation of bone-marrowresident c-kit stem cells by L-carnitine increases through secretion of VEGF IL6, IGF-1, and TGF- $\beta$ as clinical agents in cardiac regeneration. J Biosci. 2020;45:92. https://doi.org/10.1007/s12038-020-00063-0.

33. Zhu Z, Zhao-Qi Y, Cheng H, et al. Construction of a dermis-fat composite in vivo: optimizing heterogeneous acellular dermal matrix with in vitro pretreatment. J Tissue Eng Regen Med. 2020;14(2):215-28. https://doi.org/1 0.1002/term.2986.

34. Peach M, Marsh N, Macphee DJ. Protein solubilization: attend to the choice of lysis buffer. Methods Mol Biol. 2012;869:37-47. https://doi.org/10.1007/ 978-1-61779-821-4_4.

35. Ezzatollah F, Raheleh F, Behnaz V. Alginate/gelatin encapsulation promotes NK cells differentiation potential of bone marrow resident C-kit hematopoietic stem cells. Int J Biol Macromol. 2021;177:317-27. https://doi. org/10.1016/j.ijbiomac.2021.02.131.

36. Ezzatollah F, Behnaz V, Zohreh S, et al. Interleukin-6, -8, and TGF- $\beta$ secreted from mesenchymal stem cells show functional role in reduction of telomerase activity of leukemia cell via Wnt5a/ $\beta$-catenin and P53 pathways. Adv Pharm Bull. 2020;10:307-14. https://doi.org/10.34172/apb.2020.037.

37. Rigotti G, Marchi A, GalieM, et al. Clinical treatment of radiotherapy tissue damage by lipoaspirate transplant: a healing process mediated by adiposederived adult stem cells, Plast Reconstr Surg. 2007;119(5):1409-24. https:// doi.org/10.1097/01.prs.0000256047.47909.71.

38. Kiyoshi T, Masaaki I, Teruo I, et al. Adipose-derived stromal cells inhibit prostate cancer cell proliferation inducing apoptosis. Biochem Biophys Res Commun. 2014;446(4):1102-7. https://doi.org/10.1016/j.bbrc.2014.03.080

39. Wenxiu Z, Guangli R, Lei Z, et al. Efficacy of mesenchymal stem cells derived from human adipose tissue in inhibition of hepatocellular carcinoma cells in vitro. Cancer Biother Radiopharm. 2012;27(9):606-13. https://doi.org/10.1 089/cbr.2011.1150

40. Beatrice $C$, Emmanuel R, Sandrine P, et al. Adult stromal cells derived from human adipose tissue provoke pancreatic cancer cell death both in vitro and in vivo. PLoS One. 2009;4:e6278. https://doi.org/10.1371/journal.pone. 0006278 .

41. Lin R, Wang S, Zhao RC. Exosomes from human adipose-derived mesenchymal stem cells promote migration through Wnt signaling pathway in a breast cancer cell model. Mol Cell Biochem. 2013;383(1-2):1320. https://doi.org/10.1007/s11010-013-1746-z.

42. Zhao BC, Zhao B, Han JG, Ma HC, Wang ZJ. Adipose-derived stem cells promote gastric cancer cell growth, migration and invasion through SDF-1/ CXCR4 axis. Hepatogastroenterology. 2010;57(11):1382-9. https://doi.org/1 0.1007/s11999-010-1543-x.

43. Veronica C, Alice T. Di Franco Simone et al. Tumor and its microenvironment: a synergistic interplay. Semin. Cancer Biol Ther. 2013; 23(6):522-32. https://doi.org/10.1016/j.semcancer.2013.08.007.

44. Yingying J, Zhipeng $\mathrm{H}$, Yan $\mathrm{L}$, et al. Mesenchymal stem cells in inflammation microenvironment accelerates hepatocellular carcinoma metastasis by inducing epithelial-mesenchymal transition. PLOS ONE. 2012;7:e43272. https://doi.org/10.1371/journal.pone.0043272.

45. Pia N, Tuula S, Raghu K. Tumor microenvironment and angiogenesis. Front Biosci. 2008;13(13):6537-53. https://doi.org/10.2741/3173.

46. Gehmert S, Gehmert S, Prantl L, Vykoukal J, Alt E, Song YH. Breast cancer cells attract themigration of adipose tissue-derived stem cells via thePDGFBB/ PDGFR-beta signaling pathway. Biochem Biophys Res Commun. 2010;398(3):601-5. https://doi.org/10.1016/j.bbrc.2010.06.132

47. Jeon ES, Lee $I H$, Heo SC, Shin SH, Choi YJ, Park JH, et al. Mesenchymal stem cells stimulate angiogenesis in a murine xenograft model of A549 human adenocarcinoma through an LPA1 receptor-dependent mechanism. Biochim Biophys Acta Mol Cell Biol Lipids. 1801;2010(11):1205-13. https:// doi.org/10.1016/j.bbalip.2010.08.003.

48. Keiko A, Kenichi, et al. Umbilical cord blood-derived mesenchymal stem cells inhibit, but adipose tissue-derived mesenchymal stem cells promote, glioblastoma multiforme proliferation. Stem Cells Dev. 2013;22:1370-86. https://doi.org/10.1089/scd.2012.0486.

49. Smits A, Funa K, Vassbotn FS, et al. Expression of platelet-derived growth factor and its receptors in proliferative disorders of fibroblastic origin. Am J Pathol. 1992;140(1):639-48. https://doi.org/10.1097/00000433-19920300000018.

50. Pedeutour F, Simon MP, Minoletti F, et al. Ring 22 chromosomes in dermatofibrosarcoma protuberans are low-level amplifiers of chromosome 17 and 22 sequences. Cancer Res. 1995;55:2400-3.
51. Pedeutour F, Simon MP, Minoletti F, Barcelo G, Terrier-Lacombe MJ, Combemale $P$, et al. Translocation, t(17;22)(q22;q13), in dermatofibrosarcoma protuberans: a new tumor-associated chromosome rearrangement. Cytogenet Genome Res. 1996;72(2-3):171-4. https://doi. org/10.1159/000134178.

52. Rutkowski P, van Glabbeke M, Rankin CJ, et al. Imatinib mesylate in advanced dermatofibrosarcoma protuberans: pooled analysis of two phase II clinical trials. J Clin Oncol. 2010;28:1772-9. https://doi.org/10.1200/JCO.2 009.25.7899.

53. Shimizu A, O'Brien KP, Sjöblom T, et al. The dermatofibrosarcoma protuberans-associated collagen type lalpha1/platelet-derived growth factor (PDGF) B-chain fusion gene generates a transforming protein that is processed to functional PDGF-BB. Cancer Res. 1999;59(12):3719-23. https:// doi.org/10.1182/blood-2001-12-0284.

54. Selma $U$, Thomas $M$, Jochen $U$, et al. Neoadjuvant imatinib in advanced primary or locally recurrent dermatofibrosarcoma protuberans: a multicenter phase II DeCOG trial with long-term follow-up. Clin Cancer Res. 2014:20(2): 499-510. https://doi.org/10.1158/1078-0432.CCR-13-1411.

55. Potapova O, Fakhrai $H$, Mercola D. Growth factor PDGF-B/v-sis confers a tumorigenic phenotype to human tumor cells bearing PDGF receptors but not to cells devoid of receptors: evidence for an autocrine, but not a paracrine, mechanism. Int J Cancer. 2010;66(5):669-77. https://doi.org/10.1 002/(SICI)1097-0215(19960529)66:5<669::AID-IJC15>3.0.CO;2-\#.

56. Blatti SP, Foster DN, Ranganathan G, Moses HL, Getz MJ. Induction of fibronectin gene transcription and mRNA is a primary response to growthfactor stimulation of AKR-2B cells. Proc Natl Acad Sci. 1988;85(4):1119-23. https://doi.org/10.1073/pnas.85.4.1119.

57. Folkman J. Angiogenesis: an organizing principle for drug discovery? Nat Rev Drug Discov. 2007;6(4):273-86. https://doi.org/10.1038/nrd2115.

58. Alexandra A, Per L, Christer B. Endothelial and nonendothelial sources of PDGF-B regulate pericyte recruitment and influence vascular pattern formation in tumors. J Clin Invest. 2003;112(8):1142-51. https://doi.org/10.11 72/JCl18549.

59. Simon MP, Navarro M, Roux D, et al. Structural and functional analysis of a chimeric protein COL1A1-PDGFB generated by the translocation t(17; 22)(q22;q13.1) in dermatofibrosarcoma protuberans (DP). oncogene. 2001; 20:2965-75. https://doi.org/10.1038/sj.onc.1204426.

60. Zhang Z, Wang Y, Zhang J, Zhong J, Yang R. COL1A1 promotes metastasis in colorectal cancer by regulating the WNT/PCP pathway. Mol Med Rep. 2018;17:5037-42. https://doi.org/10.3892/mmr.2018.8533.

61. Ying $Z$, Lin L, Yu J, et al. Overexpression of WNT5B promotes COLO 205 cell migration and invasion through the JNK signaling pathway. Oncol Rep. 2016;36(1):23-30. https://doi.org/10.3892/or.2016.4772.

62. Jing $\mathrm{L}$, Shen $\mathrm{J}-\mathrm{X}, \mathrm{Wu} \mathrm{H}-\mathrm{T}$, et al. Collagen $1 \mathrm{~A} 1$ (COL1A1) promotes metastasis of breast cancer and is a potential therapeutic target. Discov Med. 2018;25: 211-23

63. De Felice B, Manfellotto F, Garbi C, et al. miR-34 modulates apoptotic gene expression in Ingenol mebutate treated keloid fibroblasts. Mol Med Rep. 2018;17:7081-8. https://doi.org/10.3892/mmr.2018.8749.

64. Kilroy Gail E, Foster Sandra J, Wu X, et al. Cytokine profile of human adipose-derived stem cells: expression of angiogenic, hematopoietic, and pro-inflammatory factors. J Cell Physiol. 2007;212:702-9. https://doi.org/10.1 002/jcp.21068.

65. Scavelli C, Vacca A, Di Pietro G, et al. Crosstalk between angiogenesis and lymphangiogenesis in tumor progression. Leukemia. 2004;18(6):1054-8. https://doi.org/10.1038/sj.leu.2403355.

66. Cross MJ. FGF and VEGF function in angiogenesis: signalling pathways, biological responses and therapeutic inhibition. Trends Pharmacol Sci. 2001; 22(4):201-7. https://doi.org/10.1016/S0165-6147(00)01676-X

67. Bussolino F, Di Renzo MF, Ziche M, Bocchietto E, Olivero M, Naldini L, et al. Hepatocyte growth factor is a potent angiogenic factor which stimulates endothelial cell motility and growth. J Cell Biol. 1992;119(3):629-64. https:// doi.org/10.1083/jcb.119.3.629

68. Pepper MS, Ferrara N, Orci L, Montesano R. Potent synergism between vascular endothelial growth factor and basic fibroblast growth factor in the induction of angiogenesis in vitro. Biochem Biophys Res Commun. 1993; 189(2):824-31. https://doi.org/10.1016/0006-291x(92)92277-5.

69. Wojta J, Kaun C, Breuss JM, Koshelnick Y, Beckmann R, Hattey E, et al. Hepatocyte growth factor increases expression of vascular endothelial growth factor and plasminogen activator inhibitor-1 in human keratinocytes and the vascular endothelial growth factor receptor flk-1 in human 
endothelial cells. Lab Investig. 1999;79(4):427-38. https://doi.org/10.1007/ s001090050366.

70. Xin X, Yang S, Ingle G, Zlot C, Rangell L, Kowalski J, et al. Hepatocyte growth factor enhances vascular endothelial growth factor-induced angiogenesis in vitro and in vivo. Am J Pathol. 2001;158(3):1111-20. https://doi.org/10.101 6/S0002-9440(10)64058-8.

71. Van Belle E, Witzenbichler B, Chen D, Silver M, Chang L, Schwall R, et al. Potentiated angiogenic effect of scatter factor/hepatocyte growth factor via induction of vascular endothelial growth factor: the case for paracrine amplification of angiogenesis. Circulation. 1998;97(4):381-90. https://doi. org/10.1161/01.CIR.97.4.381.

72. Zhao M, Sachs PC, Wang X, Dumur Cl, Idowu MO, Robila V, et al. Mesenchymal stem cells inmammary adipose tissue stimulate progression of breast cancer resembling the basal-type. Cancer Biol Ther. 2012;13(9): 782-92. https://doi.org/10.4161/cbt.20561

73. Eterno V, Zambelli A, Pavesi L, Villani L, Zanini V, Petrolo G, et al. Adiposederived mesenchymal stem cells (ASCs) may favour breast cancer recurrence via HGF/c-Met signaling. Oncotarget. 2014;5:613-33. https://doi. org/10.18632/oncotarget.1359.

74. Eva K, Lilly-Claire B, Inka Z, et al. The impact of human adipose tissuederived stem cells on breast cancer cells: implications for cell-assisted lipotransfers in breast reconstruction. Stem Cell Res Ther. 2017;8:121. https:/ doi.org/10.1186/s13287-017-0579-1.

\section{Publisher's Note}

Springer Nature remains neutral with regard to jurisdictional claims in published maps and institutional affiliations.

Ready to submit your research? Choose BMC and benefit from:

- fast, convenient online submission

- thorough peer review by experienced researchers in your field

- rapid publication on acceptance

- support for research data, including large and complex data types

- gold Open Access which fosters wider collaboration and increased citations

- maximum visibility for your research: over $100 \mathrm{M}$ website views per year

At $\mathrm{BMC}$, research is always in progress.

Learn more biomedcentral.com/submissions 